\title{
The 4th Hellenic Conference on the History and Philosophy of Science and Science Teaching "The Cultural Component of Science in Education": Introduction
}

\author{
Dimitris A. Koliopoulos
}

Published online: 18 July 2009

(C) Springer Science+Business Media B.V. 2009

If we adopt the opinion that science is principally a cultural object of interest to all citizens and not specialized knowledge that is appropriate only for a professional elite, we need to accept that science has long since lost any contact with everyday life, as indicated by the fact that scientific production, unlike artistic creation, is largely ignored by the general public. One of the reasons hindering science from functioning as a cultural object can be traced to scientific production being cut off from its history, since "the frenzied flight forward hinders the establishment of a permanent reference to the past, which is necessary for the creation of a tradition" (Lévy-Leblond 2004). In recent years, individual scientists, research centres and educational organisations, such as science centres and amateur science associations, working towards the dissemination of scientific knowledge and its practices are recognising, more and more, the need to reinstate communication between the modern production of scientific knowledge and the general public (including school populations), through the upgrading of the cultural component of this knowledge. One of the ways in which the cultural component of scientific knowledge can be upgraded and a scientific tradition established that will restore the cultural meaning of science, is through the introduction of elements of the history and philosophy of science into the teaching of science.

Within this framework, we can see a steady increase in the interest shown in researching the kind of contribution that the history and philosophy of science can make to the various formal or non-formal forms of science teaching. In Greece, a small but active community of researchers and educators has emerged, its main goal being to set forth issues and concerns regarding nature, the features and the content that can be provided by the relation between the history and the philosophy of science and science teaching itself. Four conferences on the history and philosophy of science and science teaching have already been held since 2001. Papers from two of these conferences have been published in special issues of Science \& Education (Skordoulis and Halkia 2005; Skordoulis 2008), while the volume in hand contains a selection of papers that were presented at the 4th Hellenic Conference on the History and Philosophy of Science and Science Teaching, organised by

D. A. Koliopoulos $(\bowtie)$

Patras University, Patras, Greece

e-mail: dkoliop@upatras.gr 
Patras University's Department of Educational Sciences and Early Childhood Education and held between 5-7 October 2007 at the University of Patras. Approximately 150 people took part, including researchers of the history and philosophy of science, researchers of science education, as well as educators and education executives. In all, 55 papers were presented which were then published as a volume. These papers were divided into six thematic segments, namely: (a) research activities related to the history and philosophy of science; (b) research activities related to the introduction of elements of the history and philosophy of science into teaching; (c) innovative teaching proposals that include elements of the history and philosophy of science; (d) research activities and/or innovative proposals regarding education or training of teachers in relation to the introduction of elements of the history and philosophy of science into teaching; (e) research activities and/ or innovative teaching proposals concerning "Science, Society and Technology"; and (f) research activities and/or innovative teaching proposals in relation to "Art and Science".

Even though each one of the thematic segments mentioned above displays epistemological and methodological peculiarities that distinguish it from the others, the papers presented at the conference, and especially the papers selected and included in this issue of Science \& Education, make up a corpus of material regarding the interface of the fields of history/philosophy of science and science teaching. Such material can only be developed through the equal collaboration between the various fields of research and education that came together at this, as well at other, similar conferences. Kanderakis's paper, "Can Science Education Research Give an Answer to Questions Posed by History of Science and Technology? The Case of Steam Engine's Measurement", belongs to thematic segment (a) and has the distinction of exploring a problem of the history of science through the point of view of science education. "History of Science and Conceptual Change: The Formation of Shadows by Extended Light Sources", authored by Dedes and Ravanis, comes under segment (b) and refers to an empirical research project describing the planning and evaluation of a sequence of teaching activities which are built on a history of science data basis. In this teaching/learning sequence, elements related to children's thought processes during science teaching are seamlessly connected to elements from the history of ideas of science. Fauque's paper, "Introducing the History of Science at the French Middle School", belongs to thematic segment (c) and attempts an interesting presentation of the efforts being made in France to introduce elements of the history and the philosophy of science into secondary education, both on the level of the secondary education curriculum as on that of microteaching. The paper by Aduriz-Bravo and Izquierdo-Aymerich which is entitled "A Research-informed Instructional Unit to Teach the Nature of Science to Pre-service Science Teachers" and comes under thematic segment (d) describes the planning and evaluation of a sequence of teaching activities that are based on an episode taken from the history of science and are addressed to future teachers with an aim to initiate them into issues of the nature of science. Also belonging to this segment is the paper by Spiliotopoulou-Papantoniou and Angelopoulos, "Enhancement of Pre-Service Teachers' Teaching Interventions with the Aid of Historical Examples", which refers to an empirical research project exploring the possibility of future educators developing teaching material based on the history of science and using it in class. Finally, the paper by Tselfes and Paroussi entitled "Science and Theatre Education: A Cross-disciplinary Approach of Scientific Ideas Addressed to Student Teachers of Early Childhood Education" also deals with a series of teaching activities that are addressed to future teachers but comes under thematic segment (f) as it underscores the cultural dimension of the knowledge of science by linking it to the theatre.

Leaving out the first paper, which addresses a mostly theoretical issue that connects the fields of history of science and science education, the other five all focus on the question of 
the development and/or exploration of the effectiveness of teaching activities that are addressed to students or teachers and which are based on or make use of elements of the history of science. These papers belong to a field of developmental research which, in time, becomes increasingly autonomous in relation to the sectors of reference that comprise it. In essence, this field takes on the features of the research trend which, in the context of science education (and especially its Continental European and Latin American version), emerges under the term "didactical transposition" of science knowledge and practice of reference (Izquierdo-Aumerich and Aduriz-Bravo 2003). Its further development constitutes, in my opinion, a necessary (though of course not adequate) prerequisite for the wider dissemination of the cultural component of science knowledge among students, teachers and the general public. The 4th Hellenic Conference on the History and Philosophy of Science and Science Teaching made this research trend a priority.

I would like to extend my warmest thanks to Michael R. Matthews, the editor of Science \& Education, for giving me the opportunity to present selected papers from the 4th Hellenic Conference on the History and Philosophy of Science and Science Teaching to an international readership. I would also like to thank all the authors who, through their research and writing, contributed to this volume; and the reviewers of each of the submitted papers who so diligently carried out the important task of reviewing and commenting on each manuscript.

\section{References}

Izquierdo-Aumerich M, Aduriz-Bravo A (2003) Epistemological foundations of school science. Sci \& Educ 12(1):27-43

Lévy-Leblond J-M (2004) Science in want of culture. Futuribles Perspectives, Paris

Skordoulis C (2008) Hellenic studies in history, philosophy of science and science teaching: new perspectives. Sci \& Educ. doi: 10.1007/s11191-007-9134-2

Skordoulis C, Halkia K (2005) Introduction: notes on the development of history, philosophy and science teaching in Greece. Sci \& Educ 14:7-8. Special issue: selected proceedings from the 2nd Hellenic HPST conference 